\title{
A ocupação do tecido verde em núcleos urbanos coloniais (Ouro Preto e Olinda, Brasil)
}

Marcelo Almeida Oliveira*

\section{Resumo}

A temática deste artigo aborda a necessidade de conhecer e proteger o patrimônio paisagístico, particularmente, nas cidades tradicionais ou luso-brasileiras. Nesse contexto, observamos que o tecido verde, em antigos núcleos como os de Olinda e de Ouro Preto, encontra-se cada vez mais dilapidado por ocupações aleatórias e/ou clandestinas, resultando no enfraquecimento da identidade cultural e simbólica nesses lugares.

$\mathrm{Na}$ realidade considerada, salientamos que os espaços verdes fizeram e ainda fazem parte de uma história praticamente ignorada pelas instituições governamentais. Devemos reconhecer que a temática tratada representa novas oportunidades no sentido de divulgar e preservar a paisagem nos referidos lugares.

Palavras-chave: Patrimônio paisagístico e cultural. Cidades luso-brasileiras. Paisagem urbana.

The occupation of green areas in urban colonial centers (Ouro Preto and Olinda, Brazil)

\begin{abstract}
The theme of this article addresses the need to know and protect our landscape heritage, particularly, in traditional or Luso-Brazilian cities. In this context, in old urban centers such as Olinda and Ouro Preto, we can observe that green areas are increasingly dilapidated by random and/or clandestine occupations. This results in the weakening of the cultural and symbolic identity of these sites.
\end{abstract}

Taking into account this reality, we highlight that green spaces have been and continue to be part of a history, which has been practically ignored by governmental 
institutions. We should recognize that this theme represents a new opportunity to disseminate and preserve the landscape in these sites.

Key-words: Landscape and cultural heritage. Luso-Brazilian cities. Urban landscape.

\section{Introdução}

Com a artificialização crescente dos hábitos da vida contemporânea e com o afastamento dos valores culturais tradicionais, grande parte da população de moradores urbanos deixou de ter relação afetiva e íntima com os jardins, as hortas ou os pomares. Os espaços abertos, que antes eram tratados como lugares especiais e produtivos, centros de cosmicidade e reposição de energias, voltados ao lazer ou ócio ou mesmo à sociabilidade, são considerados cada vez mais como espaços expectantes, sem função. A imagem de natureza próxima, vivamente apreendida por nossos antepassados, através da experiência vivencial, tem sido gradativamente substituída pela noção de natureza distante, muitas vezes desconectada de nossas próprias origens.

No domínio das cidades classificadas ou tombadas, os meios de comunicação social não têm contribuído para a conscientização das pessoas sobre os riscos de perda da identidade e do empobrecimento da cultura. Campanhas publicitárias fundamentadas em estratégias ambientalistas acabam difundindo a ideia de que a única alternativa viável à presevação da paisagem é por meio da proteção às grandes unidades de ecossistemas nativos ou das Unidades de Conservação.(1)

As pequenas parcelas hortifrutícolas no interior da malha edificada, como os quintais, dificilmente ganham evidência nos mass media. No Brasil, esses lugares raramente são percebidos como partes de um conjunto, de uma estrutura ou de um sistema. São avaliados como quase resquícios ou sobras de terra. Essa ótica concorre para a fragmentação do patrimônio paisagístico, comprometendo a qualidade de vida de seus habitantes. 
Não podemos deixar de valorizar os espaços abertos na trama dos lugares classificados ou protegidos. Eles acentuam a noção de continuidade da forma urbana, ajudam a definir melhor os limites entre o privado e o público, ampliam a percepção dos ritmos e ciclos da vida ou a temporalidade dos fenômenos naturais, além de contribuírem para a identidade espacial, dotando as cidades de maior caráter e distinção, possibilitando uma grande diversidade de ambiências, tornando a paisagem mais marcante, viva e sensual, e proporcionando ainda ao homem novas experiências sensoriais e visões de mundo (ALFAIATE, 2000, p. 18-24, 146).

\section{A fragmentação do patrimônio paisagístico em cidades brasileiras}

$\mathrm{Na}$ atualidade, é patente a escassez das manchas verdes no tecido das cidades brasileiras, o que se torna mais evidente nas periferias urbanas. Esses espaços, geralmente desprovidos de atributos formais e qualidade de vida, são pouco atrativos e por demais áridos e hostis. Normalmente, são ambientes despojados de apegos afetivos, simbólicos e referências histórico-culturais, o que minimiza qualquer sentimento pelo lugar, ao contrário daquilo que acontece nos conjuntos sedimentados pelo tempo. A inexistência ou mesmo o enfraquecimento da identidade arquitetônica e paisagística nas cidades certamente influencia a alienação dos habitantes, repercutindo num quadro de neurose coletiva, patologia urbana e violência social (MAGALHÃES, 1996, p. 214-215).

Com o predomínio da noção de "não lugar" no meio urbano, juntamente com o desapego pelas próprias raízes, aquela situação tende a agravar-se (ASCHER, 1998, p. 174). Podemos falar da disseminação de mentalidade que leva grande parte da população a associar o aspecto histórico ao que é considerado velho ou ultrapassado. A incorporação dessa maneira de pensar bloqueia ou inibe a capacidade interpretativa das pessoas. A incidência desse fenômeno certamente tem afetado o discernimento daqueles indivíduos que pouco ou nada conhecem a respeito dos locais onde habitam, com chances de tornarem-se indutores ou promotores de práticas equivocadas. Acabam realimentando processos especulativos que incidem na fragmentação do patrimônio paisagístico. Olhemos para o que acontece nos núcleos tombados, principalmente no tocante à conservação dos espaços abertos; em diversas situações, observamos a ocorrência de costumes ou hábitos oportunistas que resultam no corte da vegetação, na 
impermeabilização do solo e na ocupação clandestina e/ou irregular dos terrenos não edificados.

Percebemos, através do contato com a população de Olinda e Ouro Preto, os motivos que levam certos moradores a optar pela impermeabilização do solo (pavimentos em cimento, lajotas cerâmicas e revestimentos de pedra). Justificam as preferências adotadas pela comodidade na manutenção da limpeza doméstica, demonstrando com isso a mudança de hábitos ancestrais nessas cidades. Alguns dos entrevistados chegam ao extremo de associar o tipo de impermeabilização utilizado com padrões de beleza difundidos pela mídia, mais especificamente, no caso da construção civil, sem atentar para os riscos dos desequilíbrios ecológicos daí provenientes. Manifestações de tal abrangência têm sido direta ou indiretamente fomentadas por interesses particulares.

Apesar de os núcleos antigos serem "preservados" por instrumentos legais, muitos moradores deixam-se guiar pelo desejo de rentabilizar ao máximo os seus imóveis. Em consequência, a paisagem fica corrompida e os valores tradicionais, enfraquecidos. Considerados pouco rentáveis, os espaços abertos sofrem os mais diversos tipos de abuso, dentre eles, a construção de acréscimos irregulares ou "puxados", de garagens cobertas, a incidência de desmembramentos clandestinos. O avanço desses problemas, além de provocar o aumento da taxa de ocupação do solo, prejudica em demasia a forma urbana e a continuidade dos atributos que particularizam os conjuntos classificados (Figuras 1 e 2). 


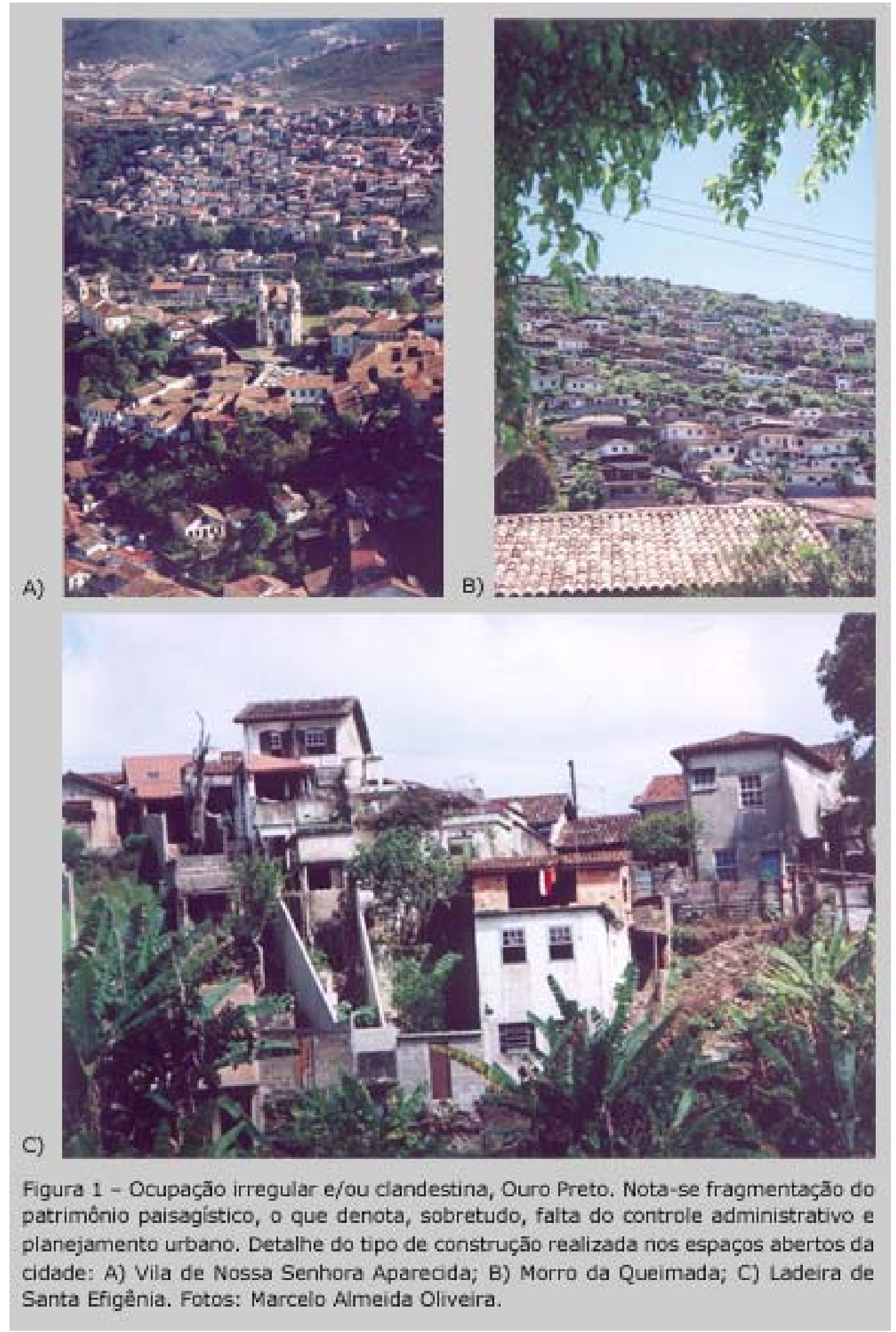




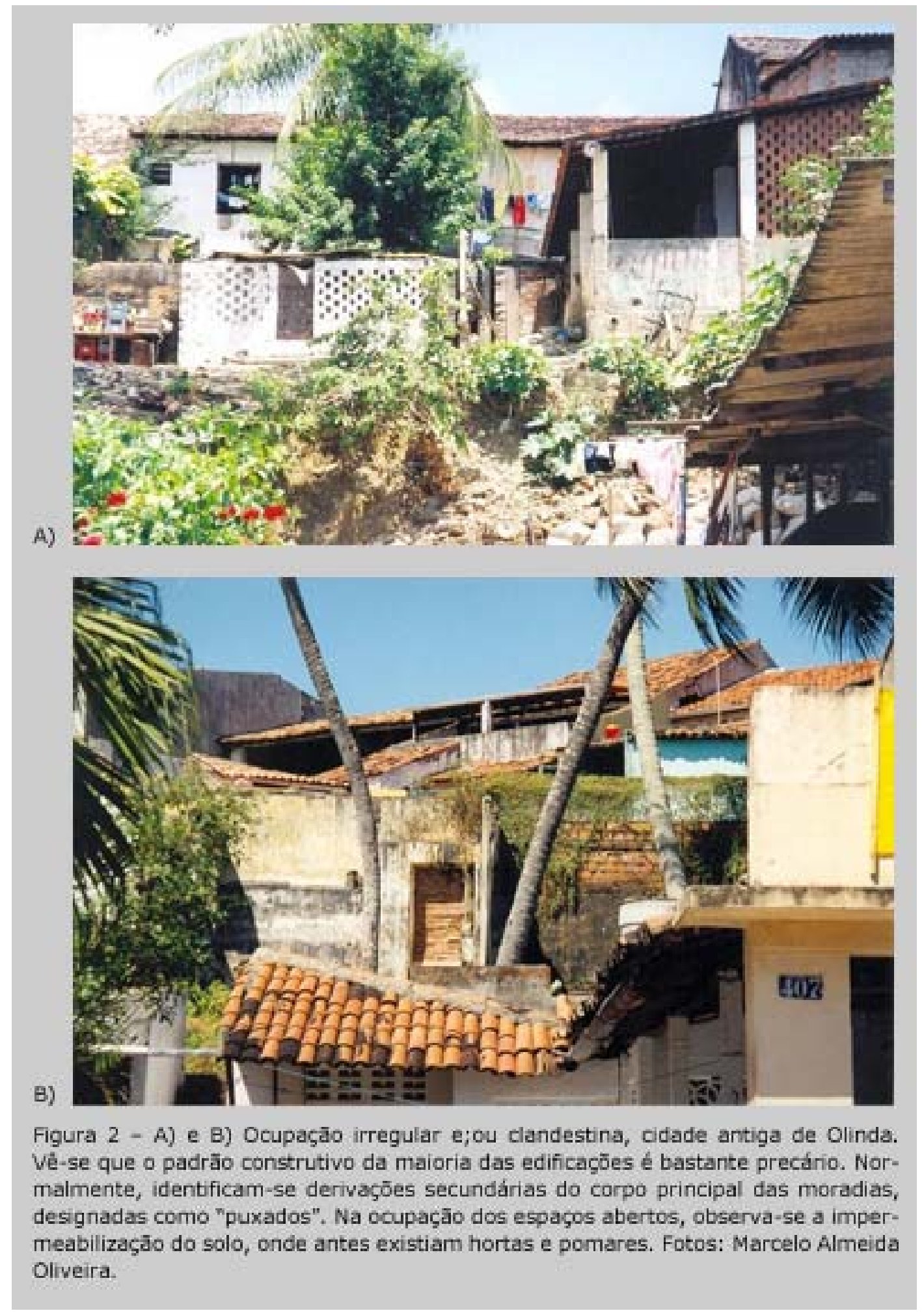

A disseminação de práticas como as mencionadas, aparentemente inofensivas na ótica de quem as concebe e divulga, representa na escala urbana o surgimento de graves danos ambientais e culturais, que comprometem a dinâmica de qualquer paisagem. Por menos prejudicial que possa parecer a ocupação das parcelas 
hortifrutícolas, essas ações acabam interferindo na integridade do patrimônio arquitetônico e paisagístico. Com base nesses aspectos, podemos refletir sobre o modo como os núcleos antigos tombados têm sido mal preservados, repercutindo na debilidade da relação entre os espaços edificados e os não edificados, entre o homem e o lugar onde reside, entre os moradores e as tipologias tradicionais, o que tem levado ao comprometimento do caráter dos respectivos conjuntos.

Diante das questões levantadas, a administração pública deveria ter papel relevante com vista a reverter esta situação que acontece de forma indiscriminada. Se não o faz, supõe-se que exista interesse em manter um determinado nível de percepção da realidade, por assim dizer, que facilite a permanência de iniciativas ligadas à especulação imobiliária, talvez a maior responsável, depois da ignorância ou do não reconhecimento do valor cultural, histórico e patrimonial dos espaços abertos, pela fragmentação ou pulverização do patrimônio paisagístico.

\section{0 desrespeito pelos condicionantes ecológicos}

No âmbito dos núcleos antigos de Olinda e Ouro Preto, não podemos deixar de refletir sobre a segregação cultural, física e social, existente e bastante visível em relação às periferias. Se os conjuntos denominados de Patrimônio da Humanidade ficam distinguidos com tão honrada condição admitida pela UNESCO (United Nations Educational, Scientific and Cultural Organization), isso deveria ser incentivo a seus administradores, para promoverem uma integração mais justa e coerente entre as partes e o todo, pautada pela requalificação do espaço e pela coesão de componentes essenciais da paisagem. As contradições, no entanto, permanecem acentuadas, inclusive pela proteção exclusiva a certos setores específicos, periodicamente conservados segundo procedimentos técnicos que valorizam principalmente as permanência das edificações "notáveis". A realidade observada nesses lugares é reflexo do modo de pensar ou conceber a paisagem, cada vez menos humana, mais artificial, musealizada e plastificada, prejudicando sobremaneira a continuidade da forma urbana, comprometendo até mesmo sua funcionalidade.

Essas ações, disseminadas e defendidas num determinado âmbito da cidade, parecem-nos sem cabimento, principalmente ao observarmos as rupturas e 
segmentações que ocorrem em seu tecido. Referimo-nos, mais particularmente, ao avanço da ocupação aleatória de caráter clandestino nos espaços abertos. O fato não pode ser avaliado como algo esporádico, sem importância, como, aparentemente, tem sido considerado. Repercute sobretudo no aumento progressivo de processos erosivos e na instabilidade do solo, representando riscos de vida para os moradores, além de prejudicar a continuidade de componentes culturais e ecológicos no meio urbano.

A cultura da falta de planejamento, que assola a realidade dos municípios brasileiros, tem influenciado o agravamento do quadro, refletindo-se numa urbanização fora de controle que vem acontecendo ao longo das últimas décadas. $A$ questão do deficit habitacional é apontada como um dos principais motivos relacionados à invasão de terrenos particulares e públicos, mas que não livra de responsabilidades as instituições administrativas, no tocante ao ordenamento da forma urbana.

\section{Ouro Preto e Olinda exemplicados}

No caso de Ouro Preto, causa-nos surpresa saber da elaboração de uma Carta Geológica, criada na década de 1980, que poderia ter sido utilizada como instrumento urbanístico, dentre outros, para direcionar o uso e a ocupação do solo, pois indicava os riscos potenciais de construções em determinados locais, que já estavam em processo de invasão desde aquela época. Contudo, a proposta nunca chegou a ser regulamentada pela administração municipal. As consequências do descaso político-administrativo são bastante visíveis na atualidade. Vários trechos da serra de Ouro Preto foram ocupados aleatória e clandestinamente. Não se conservaram nem se respeitaram as muitas ruínas históricas de moradias e sistemas de contenção e drenagem, como as que existiam em locais onde se realizavam atividades de extração mineral durante o século 18 (SOBREIRA, 1989, p. 12-13).

O que de fato aconteceu foi devido às omissões, aos oportunismos e às permissividades na gestão do patrimônio paisagístico. Foram desprezadas orientações ou recomendações técnicas fornecidas tanto pelos geólogos da Universidade Federal de Ouro Preto, quanto por arquitetos e urbanistas, dentre 
outros profissionais (CARVALHO, 1982). No passado, foram franqueados terrenos de alto risco para moradias, em zonas potencialmente instáveis e susceptíveis a escorregamentos, os quais sucedem principalmente em épocas de grande precipitação pluviométrica. As encostas deveriam ter sido lugares protegidos pela função que desempenham, relativa ao abastecimento de aquíferos. A recarga dos mananciais garantia a rega dos jardins, hortas/pomares e o suprimento de água em casas térreas e sobrados, por meio dos chafarizes. A captação do recurso hídrico, in natura, encontra-se prejudicada pela contaminação causada por esgotos domésticos não tratados, que se infiltram periodicamente no solo.

Consideramos que se tornam imprudentes a administração e a preservação do patrimônio urbano dessa maneira, negando a existência de componentes ecológicos. Não é coerente adotar o olhar do turista como único parâmetro para direcionar ações de melhorias urbanas, geralmente restritas aos lugares onde se concentram as edificações a serem preservadas. Como especialistas, devemos estar atentos para a ocorrência do processo de degradação do conjunto arquitetônico e do patrimônio paisagístico. É impossível ignorar as consequências da ocupação clandestina, que compromete não só o bem-estar e a segurança dos moradores, mas também a continuidade da forma urbana.

O núcleo antigo de Olinda não nos parece tampouco estar em melhores condições. Sobressai quase como um enclave verde, à beira mar, contornado por zonas urbanas não planejadas. (2) Basta aventurarmo-nos fora de seus limites para perceber como as diferenças ambientais, arquitetônicas, culturais, físicas e sociais são alarmantes. A legislação urbanística que trata da manutenção do núcleo protegido é, de certa maneira, responsável pela segmentação das partes, pelo fato de não levar em conta a importância da preservação da continuidade ecológica na malha edificada, bastante comprometida no passado por ações de aterramento de zonas alagadiças e pela retirada da vegetação nativa em diversos trechos. Assim, os bairros periféricos encontram-se implantados a partir de demandas aleatórias e casuísticas do mercado imobiliário. São locais adensados e áridos, com predominância de edificações de baixo padrão construtivo, principalmente nos trechos invadidos, onde a qualidade de vida é bastante precária. 
Esse quadro tem se agravado desde a década de 1960. Em relação à degradação da paisagem, podemos dizer que a omissão dos gestores é tão danosa quanto a adoção de certas medidas de ordem político-administrativas, de cunho desenvolvimentista, implementadas pelos próprios administradores. É o que parece ter acontecido com a implantação da Avenida Pan-Nordestina, na década de 1970, concebida para interligar a cidade de Olinda a Recife. Construiu-se tal empreendimento em trecho de manguezal. $\mathrm{Na}$ empreitada da obra, foram completamente fragmentados os terrenos de antigas chácaras às margens do rio Beberibe, caracterizadas pela topografia quase plana do lugar. Citamos o exemplo de uma delas, a chácara do Senhor Pereira, cuja edificação permanece como a atual sede do Centro de Educação Musical de Olinda. De acordo com o ordenamento preexistente, a moradia articulava-se, através de uma grande alameda de palmeiras, ao viveiro de peixes, construção bastante utilizada em propriedades próximas aos rios. O mencionado eixo servia para dispor os espaços produtivos e de recreio. De um lado ficavam o jardim e o pomar, composto de araçás, coqueiral, guajirus, mangueiras, dentre outras espécies. De outro, os criatórios e a pastagem. A cacimba ligava-se a um cata-vento, na parte mais baixa da parcela, o que possibilitava a retirada de água do poço mediante ação eólica. A partir da implantação da malha viária, que seccionou essa gleba, verificamos que a frente da casa, voltada para a estrada velha do Salgadinho, passou a ser a parte dos fundos. Houve uma completa inversão no posicionamento original do edifício (NOVAES, 1990, p. 76-77). (3)

\section{Interferências antrópicas na estrutura ecológica de antigos núcleos}

Não podemos deixar de observar as consequências advindas do somatório de atos praticados isoladamente, que têm prejudicado a configuração e a conformação da cidade, além de comprometer a habitabilidade do meio urbano. É necessário entendermos que quaisquer alterações no equilíbrio de um sistema afetam, em cadeia, as partes estruturantes do conjunto.

Assim, podemos considerar a análise da pesquisa feita por Jaime de A. Gusmão Filho, realizada no setor tombado de Olinda, em que foram estudadas as possíveis causas da ocorrência de danos materiais em alguns monumentos arquitetônicos, 
como a Igreja do Carmo, o Convento de São Francisco e o Mosteiro de São Bento (GUSMÃO FILHO, 2001, p. 13-19).

Sem avaliar os pormenores do referido trabalho, constatou-se uma maior incidência de aberturas de fendas na estrutura arquitetônica dos monumentos situados, sobretudo, nas proximidades dos taludes, locais mais susceptíveis a lentos movimentos oriundos da instabilidade do solo. Os resultados dos estudos elaborados (fisiográficos e geológicos) indicaram não haver somente uma causa responsável, mas um conjunto de problemas envolvidos no surgimento desse fenômeno natural. Dentre eles sobressai o fator antrópico, talvez como o principal motivo da modificação de antigas condições do equilíbrio ecológico, alterado nas últimas décadas devido à intensa urbanização que teve lugar no núcleo antigo de Olinda e em sua envolvência.

Além de as ocupações terem prejudicado a estabilidade do relevo local, a partir de aterros e cortes feitos aleatoriamente, provocaram elas também a derrubada de árvores de grande e médio portes, que ajudavam a fixar o solo com a trama de suas raízes. As interferências resultaram em escorregamentos de encostas, que afetaram todo o conjunto construído. Diante dessas evidências, deve-se valorizar os espaços abertos como locais estratégicos do tecido urbano, a fim de evitar o avanço do processo erosivo e de favorecer a infiltração de águas pluviais em aquíferos superficiais e subterrâneos, além de manter o modo de vida tradicional do lugar. $\mathrm{O}$ que, a princípio, pareceu ser um acontecimento isolado, visível apenas na envolvência dos monumentos, revelou-se como uma questão bem mais complexa, devido principalmente à ação do homem, que tem afetado o equilíbrio da estrutura da paisagem, influenciando até mesmo a redução do abastecimento de água potável na cidade.

Lembremos que Olinda se vê constantemente prejudicada pela deficiência do suprimento de água, fenômeno conhecido desde o período colonial, cuja situação se tem agravado devido à sobrecarga de exploração dos lençóis freáticos, cada vez mais rebaixados em relação ao nível piezométrico inicial. Possivelmente, a irracionalidade dos métodos de captação tem levado à alteração do perfil geológico, causando movimentos de acomodação nas camadas do solo (GUSMÃO FILHO, 
2001, p. 13-19, 41-57, 107-120, 137-144). (4) Esses aspectos reforçam a necessidade de proteção do tecido verde como um todo integrado. Não nos podemos iludir com ações que visam a preservar o patrimônio coletivo e público de maneira compartimentada e setorial, privilegiando a continuidade de alguns componentes em detrimento de outros, como tem acontecido na maior parte das vezes. É necessário encontrarmos outras alternativas para planejar e conservar os conjuntos patrimoniais que, na maioria dos casos, são considerados objetos isolados, desconectados de um contexto maior. Torna-se premente considerá-los a partir da noção de unidade ecológico-estética-cultural da paisagem, tendo em vista a permanência do caráter desses lugares, em cujos tecidos destacam-se antigas parcelas do sistema tradicional de produção e subsistência (TELLES, 1994, p. 3134). Na realidade brasileira, a forma de povoados, vilas e cidades coloniais refletia a articulação entre os espaços abertos, geralmente constituída a partir de sequências, contínuas e descontínuas, visando à obtenção do melhor aproveitamento das potencialidades ou dos recursos naturais de cada lugar.

Na fundação dos primitivos núcleos urbanos, o conhecimento pragmático, adquirido em função dos esforços de sobrevivência num determinado sítio, influenciava o homem na escolha de locais propícios ao desempenho de várias funções, comércio, lazer, moradia, produção agrícola, proteção. Em consequência, os conjuntos construídos expressavam a adequação da forma aos condicionantes naturais. Eram respeitadas as aptidões de cada lugar. A consciência de tal traço leva-nos a identificar, com maior acuidade, o que tem acontecido em núcleos antigos tombados mediante o comprometimento de suas respectivas estruturas biofísicas, cada vez mais prejudicadas pela ocupação aleatória do tecido verde.

\section{A continuidade das parcelas verdes em xeque}

Frente ao problema que se apresenta, somos levados a crer que estamos diante de uma situação limite, o que requer esforços concentrados para reverter a falta de controle do crescimento urbano. Quanto ao papel do técnico, ligado ao planejamento da cidade, ele consiste, além de outras atividades, na defesa de seus componentes fundamentais. Planejar o todo significa manter, com coerência e sentido, a integração entre aspectos culturais e naturais. Certamente, a adoção desse princípio pode contribuir para a reorientação de práticas da administração municipal, que se 
repercutem na elaboração de planos de zoneamento alheios ao continuum naturale (CABRAL, 1982, p. 36, 38, 41-43). Essa noção leva-nos a tratar o espaço urbano como um conjunto específico de elementos, conectados entre si, segundo visão sistêmica e princípios da biologia/ecologia e cultura. É importante relembrar que o todo não é uma mera soma das partes, e a desestabilização setorial de qualquer subestrutura altera em cadeia o restante do conjunto.

Com base nos pontos levantados, torna-se ambígua e contraditória a frágil existência da cobertura vegetal em núcleos antigos, como os de Olinda e Ouro Preto, principalmente diante da importância do patrimônio paisagístico para a conservação da qualidade de vida nesses lugares. Podemos falar das vantagens da permanência dos tecidos verdes no meio urbano, como a produção de frutas, legumes e verduras a reduzidos custos, o lazer e o relaxamento àqueles que se dedicam à causa da agricultura, para além do desenvolvimento da percepção sensorial, tudo isso reforçando o sentimento de afetividade dos habitantes em relação aos lugares onde residem. A manutenção dos espaços abertos também promove a reciclagem de água e de matéria orgânica, favorecendo ainda o equilíbrio do microclima, através da evapotranspiração e a redução da incidência de deslizamentos e erosões nas encostas ocupadas. (5)

Nesse quadro, a ocupação clandestina e/ou irregular vem ameaçar a continuidade das parcelas hortifrutícolas. Introduzimos esse tema a partir da problemática do fortalecimento do direito da propriedade privada, enquanto afirmação de uma mentalidade individualista. Os interesses particulares geralmente são colocados acima de valores coletivos e públicos, resultando isso na ocupação indiscriminada de antigas parcelas, comprometendo a forma urbana e reduzindo as possibilidades de convívio do homem com a paisagem. Outros problemas agravam a situação. Aquilo que sucede em Olinda e Ouro Preto acontece igualmente em diversas outras localidades do Brasil. Os habitantes não se encontram devidamente preparados para entender o significado da preservação patrimonial, o que pressupõe o cumprimento de deveres e direitos e a defesa de valores em favor da coletividade.

Diante disso, torna-se árduo o papel do Estado na regulação de conflitos e interesses de certos grupos sociais, pouco dispostos a cooperarem com a 
administração pública, na tarefa de proteger componentes culturais e naturais da paisagem. Nesse universo, encontram-se tanto moradores desejosos de individualizar ao máximo suas aspirações de bem-estar, quanto aqueles que necessitam contar com condições básicas de vida. Muitos residentes, adeptos da noção do Estado paternalista, desconhecem as dificuldades administrativas e financeiras da máquina pública que, sem recursos, não tem como suprir a maioria das demandas sociais. Isso restringe a capacidade de intervenção e de investimento do governo municipal. Em Olinda, por exemplo, a situação é agravada, sobretudo, pelas precárias condições sócio-econômicas da maioria da população. Outro problema é a baixa arrecadação de impostos. (6)

$\mathrm{Na}$ esfera do particular, a vigência do modelo de família nucleada, que agrega sempre novos parentes num mesmo domicílio, influencia a redução do tecido verde no meio urbano, além de repercutir no aumento da taxa de impermeabilização e de ocupação edificada do solo e no crescente corte de árvores frutíferas. Refira-se ainda ao elevado custo da residência, relativo ao aluguel, à compra ou à venda das propriedades no mercado imobiliário, fenômeno que se tem vindo igualmente a agravar. Não nos podemos esquecer do crescente número de remodelações em antigos imóveis, que se ampliam em toda a área, afetando drasticamente desta forma a permanência dos pomares. O somatório de todas essas questões tem prejudicado a dimensão existencial dos lugares, o que faz parecer nostálgico o seguinte registro, que demonstra a mudança do modo de vida na cidade de Olinda.

(...) Recordo-me com saudosismo do quintal de laranjeiras e do cafezal em flor. Que imagens lindas! são lembranças vivas, que faço questão de manter na memória. O quintal, como espaço de convívio, era sombreado por árvores, tinha cadeiras e redes. Algo que permitia o verdadeiro descanso ou refestelo, onde as crianças brincavam. São algumas dessas imagens que impregnam as poesias brasileiras. Infelizmente, o hábito do convívio com a parte externa da moradia está se perdendo. Construções têm sido feitas sem a menor preocupação em recriar as características da arquitetura tradicional. Não há o respeito pela topografia dos lugares. Em Olinda, é necessário que a população esteja consciente da preservação do verde e possa participar de sua continuidade na paisagem (...). (7) 


\section{Problemas e desafios}

Sabemos que a grande maioria da população residente na cidade-patrimônio não está devidamente conscientizada a respeito da importância da preservação dos respectivos conjuntos. Muitos moradores tratam os espaços abertos no diminutivo, como "quintaizinhos". Frente aos empecilhos e interesses particulares, alguns desses locais apresentam-se constantemente abandonados. Outras questões devem ser assinaladas, tais como: o comprometimento do tecido verde nos lugares pesquisados, o precário nível técnico dos projetos arquitetônicos executados, o que tem prejudicado o aproveitamento das potencialidades do patrimônio paisagístico. Em linhas gerais, a atuação do arquiteto é mínima, devido à concorrência de outros especialistas, nem sempre habilitados para realizarem, com coerência e criatividade, a adequação entre as demandas solicitadas pelo setor privado e as exigências legais estabelecidas pelo poder público. É fundamental a participação de profissionais que tenham postura crítica e visão ampla, para lapidar vontades personalistas de proprietários e buscar soluções projetuais que integrem as partes no todo. É um desafio que deve ser tratado a partir de uma metodologia rigorosa de trabalho, envolvendo a avaliação de propostas arquitetônicas e a continuidade do património paisagístico.

No âmbito do poder público, existem determinados procedimentos que merecem reflexão. Muitas práticas adotadas pela administração dizem respeito a rotinas de trabalho que, indiretamente, provocam o agravamento do quadro de apropriação indevida dos espaços abertos. Certamente, a análise morosa dos processos que solicitam a licença para a realização de reformas residenciais é uma dessas práticas. Induz os descaminhos da construção clandestina. Muitas vezes, a concessão do registro para a execução da obra é obtida depois de ela estar já concluída. $\mathrm{O}$ acontecimento do fato em si sugere a defasagem entre a condição ideal de trabalho e aquilo que, realmente, acontece na dinâmica do dia a dia. Raramente as ocupações clandestinas são tomadas como objetos de penalização exemplar. O lugar preservado acaba sendo gradativamente descaracterizado ou desfigurado. A falta de sintonia entre interesses do Estado e de particulares gera conflitos e embates, que vão repercutir em desvios da ordem preestabelecida. 
Parece-nos oportuno comentar aqui a ineficiência da fiscalização urbana. Apesar do empenho dos técnicos que efetuam as vistorias, não se consegue coibir a realização de obras irregulares. A verificação dos motivos que levam o Estado a autuar os atos de infração ajuda-nos a compreender o avanço do problema. Observamos, por exemplo, o que acontece em Ouro Preto. Nas notificações emitidas pela Prefeitura Municipal, entre os anos de 1993 e 1995, destacaram-se como infrações: novos edifícios construídos sem a devida autorização, instalações de letreiros nas fachadas de estabelecimentos comerciais e reformas no antigo casario. A partir dos dados constatados, atentamos para essa maneira de trabalhar com a paisagem, onde o edifício continua sendo percebido como elemento de destaque. Em contrapartida, as alterações feitas nos terrenos, como a execução de aterros, cortes, terraplanagens e a retirada da cobertura vegetal, são realizadas como se nenhum dano causassem à forma do lugar. Praticamente, essas ações não se encontram registradas nos laudos do mencionado período.

Possivelmente, esse procedimento é ainda resultante do modelo de preservação adotado pelo SPHAN (Serviço do Patrimônio Histórico e Artístico Nacional), criado pela Lei $n^{0} 378$ em janeiro de 1937. Tornou-se hábito corrente da população local conservar somente a aparência dos edifícios, o que não passa de mero fachadismo. Esse termo diz respeito à utilização indiscriminada de elementos compositivos da arquitetura colonial, no tratamento externo do casario, tendo por finalidade a conservação do aspecto homogêneo do conjunto urbano (OLIVEIRA, 1997, p. 105107).

Parece-nos também prudente refletir sobre a proteção institucional conferida aos espaços abertos em Olinda. No caso, está fundamentada em matéria específica, verificada a partir da Lei municipal $n^{\circ} 4849 / 92$, cujo grau de eficácia depende do nível de interpretação conferido ao instrumento jurídico (OLIVEIRA, 2008). Essa lei foi elaborada para regular o zoneamento de uso e ocupação do solo, sem observar a continuidade das parcelas verdes no tecido urbano, como tem acontecido em várias cidades do Brasil. Assim, uma mesma zona verde pode estar compartimentada em diversos setores urbanísticos, regulados por normas ou parâmetros distintos entre si, que não estão necessariamente orientados para a integração das partes. Na leitura desse documento, temos a impressão de que a cobertura vegetal do núcleo urbano 
antigo é sobrepujado pelo valor atribuído à arquitetura monumental, principalmente a de edifícios religiosos, e a suas respectivas cercas, referentes às do Convento de São Francisco, das Igrejas de Nossa Senhora do Monte, da Sé, de Santo Antônio do Carmo, do Mosteiro de São Bento e do Seminário Arquiodicesano de Olinda. O que é caracterizado como setor verde, na malha construída, corresponde a terrenos de grandes dimensões, sejam eles privados ou públicos. Contudo, as pequenas parcelas como os quintais não são vistas como elementos fundamentais da forma urbana, apesar da existência de posturas municipais que proíbem o corte de árvores e a modificação no perfil do relevo. Toda essa situação resulta da ausência de uma política voltada para o planejamento da forma global da cidade e do município, problema que não pode ser solucionado somente com a criação de leis.

Considerando-se a questão levantada, identifica-se, também, a inexistência de apoio técnico institucional aos moradores, que não dispõem nem de conhecimentos nem de recursos suficientes para a efetivação de tarefas cotidianas, que vão desde a simples limpeza dos quintais, a poda de árvores, até o combate de fitonoses. Em Olinda, a proliferação de doenças, geralmente causadas por brocas e fungos, tem prejudicado o desenvolvimento de cajazeiras, goiabeiras e mangueiras, além de coqueiros. Os surtos de pragas na cidade também fragilizaram a ocorrência das palmeiras na paisagem, que não mais existem nos adros do Mosteiro de São Bento e do Seminário Arquiodiocesano. Os exemplares suprimidos não têm sido repostos com o plantio de novas mudas, o que causa desequilíbrios na composição da silhueta urbana. Também ocorrem modismos, com a introdução de novas espécies, como é o caso do coqueiro-anão, valorizado por ser mais produtivo do que o coqueiro-da-baía e por ocupar menor espaço nos pomares urbanos.

Supõe-se que a grande incidência de brocas, cupins, formigas e fungos, que ocorre na cobertura vegetal do conjunto patrimonial de Olinda, seja uma decorrência das alterações ambientais que vêm acontecendo na paisagem, principalmente com a redução das manchas verdes nativas, processo intensificado após a década de 1940, quando ocorreu a expansão não planejada da malha urbana, além dos limites da zona tombada. Ao longo da faixa do litoral, hoje parcelada e ocupada com edificações, havia uma grande quantidade de araçazeiros, coqueiros, goiabeiras, mangabeiras e pitangueiras, que compunham o sistema vegetal das zonas úmidas. 
Alguns danos observados, resultantes dos desequilíbrios ecológicos, podem ser tratados a partir de convênios e/ou de parcerias com instituições privadas ou públicas, no intuito de viabilizar o devido suporte técnico para minimizar ou sanar os problemas existentes. Na busca de soluções para a preservação da vegetação e das antigas parcelas hortifrutícolas no tecido urbano, é imprescindível o apoio e o esclarecimento de vários segmentos da sociedade. Nesse processo, é fundamental o questionamento da aplicação indistinta de instrumentos jurídicos não orientados para o planejamento da forma urbana como um todo. Identificamos em Ouro Preto situações que acabam por agravar o avanço da ocupação clandestina nos espaços abertos. Exemplificamos o fato a partir da aplicação da Lei $n^{0} 16 / 94$, que regulamenta a posse ilegítima de terrenos devolutos do município e cujo conteúdo é decorrente da reelaboração de outras leis criadas anteriormente, as de números 185/80, 36/84, 21/87 e 90/93 (OLIVEIRA, 1997, f.107-108). (8)

A lógica administrativa privilegia o aumento da taxa de ocupação do solo, o que sem dúvida constitui um risco no que se refere à conservação da estrutura verde em Ouro Preto e em outros lugares. A base de cálculo é também passível de críticas, pela adoção de uma alíquota única, fixada em $1 \%$ sobre o valor venal do imóvel. A taxa cobrada não estimula a preservação integral do patrimônio tombado. Situação análoga identificamos em Olinda (OLINDA; SECRETARIA DE FAZENDA; PREFEITURA MUNICIPAL, 1990, p. 21-24). (9)

Tomamos os exemplos considerados como apropriações acríticas de instrumentos jurídicos. Esse procedimento foi orientado por meio do Artigo $7^{\circ}$ da Lei $n^{0} 10.257$, de 10 de julho de 2001, que regulamentou os Artigos 182 e 183 da Constituição Federal, estabelecendo diretrizes gerais da política urbana (OLIVEIRA, 2001, p. 49).

\section{Considerações finais}

Acreditamos que deveriam existir incentivos fiscais e técnicos específicos, tendo a finalidade de compensar e promover a conservação integrada do tecido verde na malha urbana, como o decréscimo do tributo devido e a realização de atividades de assistência técnica. O sucesso de quaisquer iniciativas nesse sentido depende do envolvimento de todos, de particulares e do poder público. 
No campo do desenho urbano, independentemente das soluções técnicas a serem viabilizadas, não se pode perder de vista o conjunto, a estrutura, a forma, ou seja, o todo construído e a permanência de seus componentes fundamentais.

Levando-se em conta esse propósito, convém priorizar a busca de soluções técnicoadministrativas fundamentadas na continuidade ambiental, na defesa da estrutura ecológica no meio urbano, na manutenção da identidade dos conjuntos arquitetônicos e paisagísticos, na valorização de concepções voltadas para a integração do espaço coletivo, com o sentido de se impedir a ruptura do caráter, em particular, nas cidades distintas pelo patrimônio paisagístico.

Em suma, dada a tendência de ocupação aleatória e clandestina que se manifesta, de modo contundente, nos tecidos de lugares protegidos, alertamos sobre os riscos ambientais resultantes da invasão dos espaços abertos e da remoção da cobertura vegetal. Esse fenômeno interfere na continuidade de componentes fundamentais da forma urbana, trazendo sérios prejuízos tanto à conservação dos antigos sistemas de produção, dos mananciais, do microclima, do solo quanto à manutenção da estabilidade geológica, o que afeta diretamente a permanência da dimensão qualitativa do patrimônio tombado ou classificado, dentre outras questões. As ações setoriais, de caráter especulativo, que repercutem globalmente, devem ser evitadas, pois acabam interferindo na estabilidade e na permanência dos conjuntos urbanos.

\section{Notas}

(1) O Distrito-sede do município de Ouro Preto encontra-se cercado por três grandes Unidades de Conservação, que minimizam as possibilidades de expansão urbana. Criaram-se essas unidades para o atendimento de objetivos específicos, sem a preocupação de constituir uma estrutura verde. Nesse contexto, sobressaem: a Área de Proteção Ambiental da Cachoeira das Andorinhas, que possui 18.700 hectares, fundada por Decreto Estadual $\mathrm{n}^{\circ}$ 30.264, de 16 de outubro de 1989; o Parque Estadual do Itacolomi, com 7.543 hectares, estabelecido a partir da Lei Estadual $n^{0} 4.495$, de 14 de junho de 1967, e a Estação Ecológica do Tripuí, com área aproximada de 337 hectares, instituída por Decreto Estadual n 19.157, (c.1981).

(2) Cerca de $70 \%$ do município de Olinda encontra-se dentro do perímetro urbano. Devido à proximidade com a Região Metropolitana de Recife, alguns bairros, como: Casa Caiada, Jardim Atlântico e Novo, são considerados "dormitórios". Além dessa questão, Olinda ainda enfrenta sérios problemas relativos à ocupação clandestina, que avança sobre o conjunto tombado. Os locais ecologicamente mais afetados são: o bairro de Amaro Branco, a 
Barreira do Rosário, as favelas V8, V9, V10, V11 e a ilha do Maruim. VICTOR, Plínio Araújo. Arqueólogo e morador do núcleo antigo de Olinda. Entrevista sobre espaços abertos. Olinda, set., 2005.

(3) MELLO, José Ataíde. Funcionário aposentado da Prefeitura Municipal de Olinda, líder comunitário. Entrevista sobre espaços abertos. 2005.

(4) Ressaltam-se os seguintes fatores relacionados aos movimentos das encostas de Olinda: passivos (geomorfologia e geotecnia), ativos naturais (alteração de propriedades do solo, clima e erosão) e ativos antrópicos (cortes e aterros e outras atividades de impacto).

(5) Tudo é reciclado na horta. Nunca joguei nada fora. As folhas secas e o esterco de galinha são aproveitados como matéria orgânica. Antigamente, fazia o mesmo com o esterco de porco, que era misturado com serragem (...). SILVA, Nilce Magalhães da. Moradora do núcleo antigo de Ouro Preto. Entrevista sobre espaços abertos. Ouro Preto, 2006.

(6) MELO, Almeri Bezerra de. Diretor do Centro Inter-Universitário de Estudos da América Latina, África e Ásia, filósofo/sociólogo, morador da cidade classificada de Olinda. Entrevista sobre espaços abertos. Olinda, 2002.

(7) Esse tipo de ocupação dos quintais pode ser percebido na vizinhança. No terreno ao lado, há menos de 40 anos atrás, o espaço livre, entre duas edificações existentes, era constituído por pomares. Nesse intervalo de tempo, derrubaram-se as fruteiras. No local, construíram-se mais três novas habitações e o solo ficou impermeabilizado. O que aconteceu em Olinda, também ocorreu em diversos bairros de Recife, como o Pina, prejudicando a qualidade de vida nesses lugares (...). MELO, Almeri Bezerra de. Diretor do Centro InterUniversitário de Estudos da América Latina, África e Ásia, filósofo/sociólogo, morador da cidade classificada de Olinda. Entrevista sobre espaços abertos. Olinda, 2002.

(8) Esses instrumentos jurídicos tinham a finalidade de legalizar a posse fundiária, desde que cumpridas as exigências estipuladas, dentre elas: a obrigatoriedade, para o requisitante, de apresentar documentos comprobatórios da quitação de taxas públicas e a realização de benfeitorias no terreno ocupado. Importa perceber que o caminho aberto pelo referido recurso legal acelerou o processo de ocupação irregular e/ou clandestina na cidade. Grande parte dos lotes, legitimados no período compreendido entre os anos de 1993 e 1996, encontra-se situada nos seguintes bairros: Alto da Cruz, Bauxita, Morro da Queimada, Padre Faria e Santa Cruz, sendo que alguns deles apresentam sérios riscos geológicos. A outra constatação refere-se ao Código Tributário Municipal, Lei $n^{\circ}$ 106/94. Segundo a análise do conteúdo do Artigo 83, a cobrança do Imposto Predial e Territorial Urbano que incide sobre terrenos não edificados é comparativamente maior que o estabelecido para as parcelas edificadas.

Para a regularização dos terrenos com benfeitorias, a Divisão de Lotes Urbanos da Prefeitura Municipal exigia do pleiteante a seguinte documentação: guia quitada do IPTU (Imposto Predial e Territorial Urbano) e uma conta de luz do imóvel, visando à certificação do endereço residencial. No caso dos terrenos sem benfeitorias, bastava apresentar recibo de compra e venda da propriedade, geralmente feita de modo clandestino, sem a anuência do poder público. Em suma, o que sucedia era a legalização do ilegal. BARBOSA, Geraldo. Funcionário da Divisão de Lotes Urbanos da Prefeitura Municipal. Entrevista sobre o Programa de Legitimação de terrenos devolutos no Município de Ouro Preto. Ouro Preto, mar., 1996. 
(9) Eu já fui avaliador de imóveis da Prefeitura Municipal de Olinda e tive uma equipe de 40 fiscais. Esse serviço era a base de cálculo do Imposto Predial e Territorial Urbano. Um terreno pouco ocupado sempre tinha um imposto maior do que as propriedades mais edificadas. O cálculo efetuado era feito levando-se em conta 1\% do valor venal da parte construída, acrescido de $2 \%$ do valor venal da parte não construída (...). MELLO, José Ataíde Funcionário aposentado da Prefeitura Municipal de Olinda. Entrevista sobre espaços abertos. Olinda, 2005.

\section{Referências bibliográficas}

ALFAIATE, Maria Teresa Amaro. Expressões dos valores do sítio na paisagem. 2000. Tese (Doutorado em Arquitetura Paisagista)-Instituto Superior de Agronomia, Seção de Arquitectura Paisagista, Lisboa, 2000.

ASCHER, François. Metapolis: acerca do futuro da cidade. Oeiras: Celta Editora, 1998.

CABRAL, Francisco Caldeira. O continuum naturale e a conservação da natureza. In: Serviços de Estudos do Ambiente. Conservação da natureza. Lisboa, 1982, p. 35-54.

CARVALHO, Edésio Teixeira. Carta geotécnica de Ouro Preto. 1982. Dissertação (Mestrado)-Universidade Nova de Lisboa, Lisboa, 1982.

GUSMÃO FILHO, Jaime de A. A cidade histórica de Olinda: problemas e soluções de engenharia. Recife: Editora Universitária da Universidade Federal de Pernambuco, 2001.

MAGALHÃES, Maria Manuela Cordes Cabêdo Sanches Raposo. Morfologia da paisagem. 1996. Tese (Doutorado em Arquitectura Paisagista)-Instituto Superior de Agronomia, Universidade Técnica de Lisboa, Lisboa, 1996.

NOVAES, Ferdinando. Olinda, evolução urbana. Recife: FUNDARPE, 1990.

OLINDA; SECRETARIA DE FAZENDA; PREFEITURA MUNICIPAL. Código tributário do Município de Olinda. 1990.

OLIVEIRA, Isabel Cristina Eiras de. Estatuto da cidade; para compreender... Rio de Janeiro: IBAM/DUMA, 2001.

OLIVEIRA, Marcelo Almeida. O patrimônio paisagístico nas cidades luso-brasileiras: um olhar sobre duas realidades, Olinda e Ouro Preto. 2008. Tese (Doutorado em Arquitectura Paisagista)-Universidade de Évora, Évora, 2008.

OLIVEIRA, Marcelo Almeida. Os valores culturais da paisagem urbana em Ouro Preto, Minas Gerais: um estudo de caso das áreas verdes na ladeira Santa Efigência e entorno próximo. 1997. Dissertação (Mestrado em Desenho Urbano)-Faculdade de Arquitetura e Urbanismo da Universidade Federal da Bahia, Salvador,1997.

SOBREIRA, Frederico Garcia. A ocupação desordenada de encostas em Ouro Preto, Minas Gerais. Revista Escola de Minas, Ouro Preto, n. 42, p. 12-16, quarto trimestre, 1989. 
TELLES, Gonçalo Ribeiro. Paisagem Global. In: ABREU, Margarida Cancela de (Coord.). Paisagem. Lisboa: Direcção Geral do Ordenamento do Território e Desenvolvimento Urbano, 1994. p. 31-45. (Colecção Estudos, 2).

\section{Créditos}

* Doutor em Arquitetura Paisagística pela Universidade de Évora - Portugal. Investigador do Centro de Estudos da População Economia e Sociedade - CEPESE/Portugal. Analista Ambiental do Instituto Estadual de Florestas - IEF/Minas Gerais/Brasil.

e-mail: maoout@yahoo.com.br, maoout@gmail.com

artigo recebido em 01/2011

artigo aprovado em 04/2011 